\title{
El rol del baúl y los registros históri- cos en Manuela Sáenz: la libertadora del libertador, de Diego Rísquez*
}

\author{
Yudis Contreras Martínez ${ }^{\mathbf{1}}$ \\ Universidad de Cartagena (Colombia)
}

Resumen

La película Manuela Sáenz: la libertadora del libertador (2000), del director venezolano Diego Rísquez, con una propuesta revisionista e innovadora trae a la pantalla grande la figura de Manuela Sáenz, para presentarla al público en una versión biográfica que se concentra en la agencia que ella tuvo durante la gesta libertadora latinoamericana, principalmente en Perú y Colombia. El hilo narrativo de la película aparenta seguir, muy de cerca, los registros históricos del período de la independencia y post independencia. Sin embargo, desde la contextualización que surge de las cartas de amor, enviadas por Simón Bolívar, sacadas del baúl de los recuerdos de Manuela, estos registros se alteran. La ambientación de varios momentos históricos de la vida del Libertador, descritos por historiadores y biógrafos,
Abstract

The film Manuela Sáenz: la libertadora del libertador (2000), by the Venezuelan director Diego Rísquez, with a revisionist and innovative proposal, brings to the big screen the figure of Manuela Saenz, to present her life to the public in a biographical version focused on the agency she had during the Latin-American liberating gesta, mainly in Peru and Colombia. The narrative thread of the film, apparently, follows very closely, the historical inscriptions of the Independence and postindependence period. However, from the contextualization emerging from the love letters sent by Simón Bolívar, taken out from Manuela's memories chest, the historical inscription is altered. The setting illustrating several historical moments of the Liberator's life, described by historians and biographers, seen

\footnotetext{
*The role of the chest and the historical record in Manuela Sáenz: la libertadora del libertador by Diego Rísquez

Recibido: 31 de octubre de 2017 - Aprobado: 22 de diciembre de 2017

${ }^{1}$ Doctora en Literatura Hispánica por la Universidad de Indiana (EE. UU.). Profesora del Programa de Lenguas Extranjeras de la Universidad de Cartagena (Colombia) e-mail: ycontrerasm@unicartagena.edu.co
} 
vistos ahora desde la narración que hace su compañera sentimental, sugieren otra verdad posible. El baúl de los recuerdos será de mucha importancia a lo largo de este análisis, ya que las cartas que en él se encuentran pueden ser vistas como documentos oficiales. Por esta razón, este artículo se concentra en revisar la función del baúl como un actante que facilita una lectura comparativa entre el período post-independencia y la situación socio-política venezolana del momento de producción de esta película.

Palabras clave: Manuela Saénz, Simón Bolívar, baúl, cartas de amor, archivo histórico now from the narration made by his partner, suggest another possible truth. The chest will be very important throughout this analysis, due to the fact that the letters it keeps could be seen as official documents. For this reason, this article focuses on a revision of the function of the chest as an actant that facilitates a comparative reading between the post-independence period and that one of the Venezuelan socio-politic situation in the moment this film was presented.

En la película Manuela Sáenz: la libertadora del libertador (2000), del director venezolano Diego Rísquez, la historia se empieza a narrar por el final. Por esta razón, la Manuela que encontramos tiene una edad avanzada y además ha quedado inválida. Según la ambientación de la película, ella vive en Paita, un puerto peruano a donde fue desterrada en 1830, después de la muerte de Simón Bolívar². En esta etapa de su vida sólo está acompañada por sus dos criadas: Natán y Jonatás. El lugar donde vive es muy humilde y el único objeto valioso que posee es un baúl, en el cual guarda las cartas de amor que Bolívar le enviara durante su vida. Este objeto será de mucha importancia en la trama de la película. A través de las cartas que en él se encuentran, Manuela vuelve, una y otra vez, a varios episodios de la vida del Libertador descritos por historiadores y biógrafos durante muchos años, para presentarlos, esta vez, desde el punto de vista de la mujer amada y desde la agencia que ella misma tuvo en la época independentista. Según lo ilustra Manuela, las cartas escritas por puño y letra de Bolívar son

\footnotetext{
${ }^{2}$ Manuela Sáenz era de Quito y fue compañera sentimental de Simón Bolívar entre 1822 y 1830. Sus nexos con el Libertador aparecen registrados en numerosas biografías históricas y biografías noveladas de Bolívar. Véase, por ejemplo, Ospina (2010). Así, como en la película Bolívar: soy yo (2002), del director colombiano Jorge Alí Triana. La contribución de Rísquez radica en que, por primera vez, se presenta la vida de Manuela Sáenz durante su exilio, después de la muerte de Simón Bolívar.
} 
documentos fidedignos, que ella percibe como si fueran escritos oficiales que avalan la verdad de los hechos históricos que ella se propone contextualizar. De esta manera, el baúl podría equipararse a un archivo histórico, del cual la protagonista extrae documentos para probar su versión de los hechos.

Desde este artículo, la revisión de los distintos momentos contextualizados en la película se hará teniendo en cuenta, primero, el cómo Manuela Sáenz posiciona su voz como la única persona conocedora de los hechos. Segundo, creando un contrapunto entre los momentos históricos ilustrados y diferentes posturas críticas en torno a la figura de Manuela Sáenz y su lugar en los textos de historia patria. Tercero, mirando de cerca cómo los conflictos socio-políticos que aparecen, aparentemente narrados como telón de fondo de una historia de amor, son el instrumento que devela un paralelo entre la situación política venezolana en la época post-independentista y el momento en que se lanza la película. Por último, examinaremos cómo uno de los personajes secundarios, Melville, es quien permite juntar las distintas partes de la historia, supuestamente narrada desde la voz de Manuela Sáenz.

A partir de una escritura epistolar que usa a su antojo, Manuela, como personaje principal y voz narrativa a la vez, establece un contrapunto entre historia y ficción, posicionándose como único testigo de los hechos. De este modo, se aprecia, por ejemplo, la entrada del ejército patriota en Quito, el 16 de junio de 1822 como un día memorable, pero no por los triunfos independentistas, sino porque le recuerda el día en que Bolívar y ella se conocieron, tal y como reposa en varias biografías de Bolívar ${ }^{3}$. Esta escena, mostrada por medio de una técnica de flash-back, basada en una remembranza del momento histórico, nos lleva a notar que el énfasis está en la pasión que se despertó entre los amantes y no en el triunfo libertario. El hecho de mostrar la vida de Simón Bolívar a través del lente de Manuela conlleva a crear una admiración hacia ella, al verla como alguien con un alto espíritu de lucha y compromiso con los postulados de nación hechos por Simón Bolívar. De igual modo, Manuela, identificada como un sujeto que se encuentra en el destierro, engloba en sí misma varios sujetos que, al igual que ella, puedan llegar a enfrentar una situación de exilio. Es decir, Manuela deja de ser vista como aquella que fue condecorada

\footnotetext{
${ }^{3}$ El biógrafo colombiano Indalecio Liévano Aguirre (2001), en su libro Bolívar, narra este momento de la siguiente manera: "Seguido por esta ola de emoción popular, Bolívar llegó a la esquina diagonal del palacio del obispo, donde una corona de laurel, arrojada desde uno de los balcones, cayó sobre él; al levantar los ojos, ellos se encontraron por primera vez con la mirada profunda, casi acariciadora, de Manuela Sáenz [...]" (258).
} 
con la orden de Cabelleresa del Sol (1822) por sus servicios a favor de la independencia latinoamericana, y se convierte en una mujer solitaria, exiliada, enfrentada a la desilusión de un amor perdido, convencida plenamente de que la razón por la que se encuentra en tal situación ha valido la pena y ha dejado un proyecto de nación por continuar.

De esta manera, podría decirse que Rísquez no sólo revisa el pasado histórico de las gestas independentistas, sino que, sutilmente, pone de relieve que las tensiones bipartidistas de la Venezuela de 1830, tal vez, no están muy distantes de las que ocurren en el año 2000, momento del estreno de la película ${ }^{4}$. Desde la puesta en escena de las tan marcadas diferencias entre Manuela Sáenz y los enemigos políticos de Bolívar, se aprecia que éstas fueron las razones para el exilio de Manuela, y para que, por consiguiente, haya quedado por fuera de la historia, según lo han registrado varios críticos literarios e historiadores. Como bien lo ilustra Inés Quintero, en su artículo "Manuela Sáenz: una biografía confiscada" (2009), con un tono crítico en torno a la caracterización que presenta Rísquez, la vida de Manuela es revisada sólo a la sombra de Bolívar. Quintero afirma que el desarrollo de la trama se centra en dos momentos cruciales de la vida de la protagonista: el día en que conoce a Bolívar y el día que él muere. Según esta crítica, esta representación hace eco a la forma en que Manuela Sáenz ha sido excluida de los textos de historia nacional por distintos autores:

En el caso particular de Manuela, esta actitud
historiográfica se vio intervenida por una restricción
estilística adicional: ocultar intencionalmente
su actuación, básicamente, porque no resultaba
ejemplarizante ni acorde con la visión impoluta
de los héroes, que Bolívar, la máxima figura de la
Independencia, se hubiese liado con una mujer de
comportamiento irregular y censurable (1).

Ampliando su cita, Quintero agrega que Manuela Sáenz era una activista política antes y después de haber conocido a Bolívar, pero que distintos autores la excluyeron de los textos de historia por una actitud chauvinista que rechazaba que las mujeres actuaran de tal modo. En diálogo con las ideas expuestas por Quintero, hay que agregar que, en una sociedad conservadora como la de fines de siglo XVIII y principios del siglo XIX latinoamericano, momento en que

\footnotetext{
${ }^{4}$ Año 2000, pleno período de gobierno del entonces presidente Hugo Chávez Frías, después de haber vivido circunstancias adversas tanto para llegar al poder como para mantenerse en él, debido a la fuerte oposición en contra de su gobierno.
} 
está enmarcada la película, una mujer que participa abiertamente en política, se viste con pantalones, fuma y toma decisiones propias, como la Manuela que muestra Rísquez, corre el riesgo de ser vista como una mujer de conducta censurable. Además, en un entorno donde la mujer debía permanecer en casa, muchas veces, al lado del esposo que, por conveniencias sociales o económicas le buscaran sus padres, Manuela Sáenz, al rehusarse a mantener la unión matrimonial con su esposo, el Dr. Thorne, para irse con su amante, de seguro era percibida con rechazo por la sociedad neogradanadina y de la Lima de su tiempo ${ }^{5}$.

Complementando esta idea de una Manuela Sáenz excluida de la historia, Pamela S. Murray, en su artículo "Loca or Libertadora?: Manuela Sáenz in the Eyes of History and Historians", anota que a Sáenz se le ha clasificado en dos tendencias: la de unos historiadores que hablan de ella de manera negativa y otros que siguen en ella la misma figura de lo que se conoce como El culto a Bolívar ${ }^{6}$. Afirma Murray que a Manuela Sáenz se le reconoce su valentía y soporte emocional sólo como compañera de Bolívar y porque le salvó la vida ante el atentado que sufriera de manos de sus enemigos políticos, el 25 de septiembre de 1828. En consecuencia, agrega Murray, sus acciones antes y después de la vida de Bolívar han sido prácticamente ignoradas:

For almost a century, historians in Spanish America had little or nothing to say about Manuela Saenz. Ecuadorian historians, in particular barely mentioned her. In surveying the work of such authors for the years between 1860 and 1940, Maria Mogollón and Ximena Narváez found only three books that mentioned the woman who had an integral part of Bolívar's inner circle (3).

La razón que da esta crítica para que no se mencione a Manuela Sáenz coincide con el análisis de Inés Quintero en que muchos historiadores no estaban de acuerdo con que se vistiera con uniforme militar, interviniera en política e hiciera fiestas con gran algarabía. Es relevante tener en cuenta que la observación de Pamela Murray

\footnotetext{
${ }^{5}$ Esta referencia de una Manuela que abandona a su esposo y se va con su amante es registrada en varias biografías de Bolívar, algunas veces, sin mucho énfasis. No obstante, desde los textos de ficción este hecho ha sido retomado varias veces: Adorable Loca (1984), de Voltes Bou; La esposa del Dr. Thorne (1987), de Romero; Nuestras vidas son los ríos (2006), de Manrrique Ardila.

${ }^{6}$ Tema recurrente en estudios historiográficos en torno a la figura de Simón Bolívar. Véase Carrera Damas (1983) y Conway (2003).
} 
apunta a revelar la crítica tan severa que se le hace a Manuela Sáenz en los textos estudiados por ella, en los cuales observa un total rechazo hacia las mujeres que no cumplieran con las normas sociales pre-establecidas.

La exaltación que Rísquez hace de Manuela Sáenz, entonces, al presentar su película en el año 2000, no parece ser casual, y por el contrario, sí muy coherente, no solo con el contexto histórico en proximidades del bicentenario de las independencias latinoamericanas, sino con el entorno venezolano de inicios del siglo XXI. En ese momento, había un gran sentido nacionalista promovido por el presidente de turno, Hugo Chávez Frías, amparado en la imagen de Simón Bolívar, y que continuó vigente durante los años consecutivos de su gobierno. Según se vio en varios diarios latinoamericanos, el 3 de julio del 2010 la imagen de Manuela Sáenz fue homenajeada por los presidentes Hugo Chávez, de Venezuela, y Rafael Correa, de Ecuador, tierra natal de Sáenz, honrándola por el apoyo que ofreció a la causa libertadora. En ese homenaje dichos presidentes recibieron en Venezuela los restos simbólicos de Manuela Sáenz, para depositarlos al lado del sarcófago de Bolívar, en Caracas. Esta actitud de elogio de ambos presidentes no es muy lejana a lo que describe Pamela Murray, en cuanto a que, en contraste con los escritores que la atacaron, también existe un grupo que, con el fin de exaltar cada acción de Bolívar, han exaltado también a Manuela como heroína. Tal actitud, afirma Murray, destaca la labor de Manuela Sáenz como mujer que acompañó a Bolívar durante tanto tiempo en la lucha por la independencia, pero, además, lleva a quienes se presentan como sus admiradores a caer en el mismo tema, pues igualmente la componen como figura de un culto heroico. En el grupo de historiadores que han enaltecido la labor de Manuela Sáenz, Murray cita a José María Cordovez, quien, en defensa de la infidelidad de Manuela, dice que el amor entre ella y Bolívar era "un amor justificado", ya que el matrimonio con su esposo, el doctor Thorne, le había sido impuesto por su padre.

Murray cita a Eduardo Posada, quien presenta a Manuela Sáenz como heroína, al ser víctima de los enemigos políticos de Bolívar, quienes la expulsaron de Colombia por haberse mantenido fiel al libertador. Por último, esta crítica cita a Vicente Lecuna, quien exalta a Sáenz como una salvadora del país al impedir que Bolívar fuera asesinado. Todas estas posiciones han buscado reivindicar la imagen de Manuela con el fin de promover una idea de nacionalismo que permitiera presentar su valentía y apoyo a la causa independentista y ampliar, consecuentemente, la mirada en torno a las mujeres en ese momento histórico. De igual modo, observa Murray que esta imagen 
reivindicadora ha servido para promover una idea de feminismo, y al mismo tiempo, para convertirse en una figura que facilita una nueva inscripción de las minorías y de los representantes de izquierda que no se acogen a los planteamientos del gobierno de turno.

\section{Manuela Sáenz y su lugar en la historia}

Además de los aspectos señalados por Murray, vale la pena mirar a Manuela desde las analogías, que, de manera más cercana, se pueden encontrar por medio de su interacción con otros personajes, entre los textos escritos y la verdad histórica que se pretende posicionar. Las relaciones que se dan a lo largo de la película entre los personajes implican que ellos también son posibles narradores de una nueva historia. Del mismo modo, los resultados que surjan de las relaciones entre Manuela y los otros personajes nos van a llevar a establecer una relación entre Bolívar y los escritos históricos que han estructurado su imagen heroica.

Es relevante anotar que la caracterización de una Manuela osada y reacia a las jerarquías sociales y políticas, como la que presenta Rísquez, no está totalmente amparada en la ficción. Al verla con un rol político tan activo, la película parecería, más bien, no alterar los registros históricos en cuanto a la descripción que de esta mujer se encuentra en los textos históricos. Al presentar varios momentos históricos, la película se va amparando en cada narración que hace Manuela, a partir de las cartas que va sacando del baúl de sus recuerdos y leyendo en voz alta. Vale la pena anotar, no obstante, que los momentos que narra hacen parte de la memoria colectiva, ya que han sido inscritos en textos de historia patria, biografías y revisiones historiográficas muchas veces. De este modo, el hilo narrativo de la película, al mostrar a Manuela Sáenz interviniendo activamente en varios asuntos políticos, aunque narre lo que ya aparece en las biografías de Simón Bolívar, pareciera reivindicar, por medio de la vida que gana Manuela con la actuación, la imagen anulada por los textos de historia. Según lo muestra Rísquez, Manuela, a título personal y desligada de Bolívar, siempre tuvo intereses políticos, y precisamente por oponerse tan fuerte a las ideas del gobierno de turno del entonces presidente de la república Francisco de Paula Santander, fue desterrada de Colombia y silenciada su voz y gestión política en los textos de historia nacional.

Rísquez, a pesar de la posición de Inés Quintero, quien ve en la película sólo una mujer a la sombra del Libertador, rescata la imagen de Manuela Sáenz, y pareciera ser a ella a quien saca del 
anquilosamiento del baúl donde están sus cartas de amor. Siguiendo el registro historiográfico, la presenta como una mujer con una toma de decisiones acertadas, aunque tuviera que hacer uso de estrategias inesperadas para quien fuera la compañera de Bolívar. De igual modo, exalta que cuando debía resolver situaciones que le concernían políticamente, Manuela Sáenz no seguía normas y jugaba todas las cartas que tuviera a su favor. Ejemplos de esta actitud se aprecian en la escena cuando se presenta disfrazada de pordiosera para hacer que Bolívar salga de una fiesta de disfraces en la que sus enemigos políticos habían planeado asesinarlo. Este hecho, altamente registrado por varios textos históricos, es la razón de ser del título de la película, pues, por haber evitado que Bolívar fuera asesinado el 25 de septiembre de 1928, fecha conocida como La noche septembrina, Manuela Sáenz ganó el título de "Libertadora del libertador".

Si bien, al llamarla con este epíteto, Rísquez se suma a la tradición histórica y sigue los registros biográficos más señalados de la vida del Libertador, también es cierto que no sólo muestra a Manuela a merced de Bolívar, sino que engrandece su rol en la historia nacional. Este performance de la protagonista sugiere que hay otra verdad histórica posible en torno a esta mujer, particularmente, y con mucha probabilidad, en torno a otras mujeres del período independentista igualmente silenciadas. Hay que observar que, aunque el director enmarca la trama de la película en varios registros históricos sobre la vida de Bolívar, posiciona a Manuela como la única voz narrativa que conecta todos los hilos de la película, y como quien conoce la verdad. De igual modo, en cuanto a la reivindicación de género, no parece ser casual tampoco que las únicas que siguieron a Manuela fueron sus dos criadas, dos mujeres a las que no les importó irse al exilio con ella. Posiciona también a Manuela como una mujer que, con Bolívar o sin él, era capaz de enfrentar las situaciones que le tocara asumir.

En la película vemos a Manuela como una mujer desafiante, vestida con uniforme militar al asistir a reuniones con los miembros del gobierno de la Nueva Granada. Esta actitud, vista como provocadora por los militares del período independentista, revoca el orden jerárquico en el que solamente estaban incluidas personas del género masculino. Además, difiere notablemente de la Manuelita vestida muy elegante, con atuendos femeninos de la época, que siempre encontramos en los museos. Por otra parte, al ser presentada por Rísquez como quien tiene el baúl, y por lo tanto, como la única que ha heredado el legado del Libertador, le otorga a Manuela una forma de poder. Ella podrá contar la historia, a su modo, porque es la única que conoce la verdad de los hechos. Nadie más ha leído las cartas que 
recibió, ni sabe tampoco si es cierto o falso lo que ella relata. De igual modo, por medio del baúl, le otorga la posición de única dueña de la verdad, ya que será ella quien pueda hacer llegar la información a los demás. Por consiguiente, dará a conocer la historia exaltando los hechos de su preferencia.

En consonancia con lo expuesto, el baúl de los recuerdos de Manuela puede cumplir con las mismas funciones de un archivo histórico, como se ha mencionado previamente. El baúl contiene las cartas, y el relato basado en las cartas no sólo le da poder, sino que le permite mostrar que quienes tienen los documentos originales son los que se han presentado como los verdaderos conocedores de la historia. En relación con la idea del poder que da el archivo, Roberto González Echavarría (1990), en su libro Myth and Archive, afirma que muchas de las novelas latinoamericanas hacen uso de la figura del archivo para sustentar la trama que desarrollan y crear así, por medio de éste, una idea de verosimilitud. González Echavarría encuentra en varias novelas latinoamericanas un discurso antropológico que busca presentar tales escritos como una prueba de legalidad o autoridad. A través de ejemplos como el pergamino de Melquiades, en Cien años de soledad, y los folios despezados que se encuentran en la alcaldía de Riohacha, como parte de la denuncia al asesinato de Santiago Nasar, en Crónica de una muerte anunciada, observa cómo el hallazgo de un documento escrito avala una historia que ha sido contada oralmente.

En el caso de Manuela, en forma contraria a la idea presentada por Echavarría, el discurso escrito es el que requiere respaldo del discurso oral para crear verosimilitud. Es decir, lo escrito en torno a Bolívar y las gestas independentistas no parece ser suficiente o está devaluado. Por lo tanto, es necesario acompañar la escritura con la entonación, la dicción, el énfasis de cada momento descrito, y sobre todo, con la pasión que busca cambiar la perspectiva que se tenga de tales momentos. En el performance que lleva a cabo Manuela al leer las cartas, que son la prueba de la verdad que ella conoce, no basta decir que fueron escritas por el propio Bolívar, sino que las lee en voz alta, como para que muchas personas la escuchen y para que sea su voz ese elemento que define que el discurso escrito es certero. En consonancia con las ideas expuestas en Myth and Archive, está claro que el punto clave es la idea de crear un discurso verosímil que gane aceptación desde la autenticidad de los documentos que, en este caso, Manuela muestra como originales.

El análisis de Gonzáles Echavarría, además de apuntar a que la escritura ficcional amparada en documentos científicos o históricos 
apoya el concepto de verosimilitud, expone que el discurso antropológico busca, de igual modo, crear personajes míticos que permitan cerrar un ciclo de vida y empezar un mundo nuevo. En su ejemplo puntual, exalta el caso de la nueva estirpe de los Buendía, en Cien Años de Soledad, que empezará después de que nazca el último hijo/a de su generación, el que se cree nacerá con cola de puerco. En palabras de Echavarría, el archivo es un mito porque tiene que ver con la concepción de un mundo no estudiado de culturas pasadas que, según el lenguaje antropológico, sería un hallazgo digno de ser registrado e interpretado como un gran acontecimiento cultural y social. En el caso de la película Manuela Sáenz: la libertadora del libertador, la presencia del baúl abre la posibilidad a ese mundo nuevo y puede verse como dos partes que se complementan y que, de manera similar, crean un punto de encuentro con las novelas del corpus analizado en el texto de González Echavarría.

El hecho que el baúl tenga varios documentos que se van extrayendo poco a poco define que la historia se terminará de contar cuando muera Bolívar o cuando muera quien narra. El baúl, entonces, funciona como el objeto que se abre para re-contar, a partir de la primera carta, una historia vieja que encierra un pasado anquilosado y como uno que a la vez se re-abrirá, a partir de la muerte de Bolívar, para contar una nueva historia. Esta nueva versión de la historia, avalada tanto por la escritura como por una versión oral, será contada desde una sugerente y necesaria re-escritura de los hechos que se plantea dar a conocer. Consecuentemente, los nuevos escritos llevarán a una re-lectura histórica que busca cambiar el curso de la verdad instaurada en la memoria colectiva latinoamericana en relación con Manuela Sáenz y Simón Bolívar, a lo largo de lo que está escrito en los textos de historia patria. En este sentido, el énfasis es que la película, desde la figura del baúl- archivo, establece que existe un viejo mundo que reposa en el baúl y un nuevo mundo enmarcado en las cartas que salen del baúl y que podrán volver a narrar el principio y el fin de la relación de Manuela Sáenz y su amado Bolívar.

El baúl, visto como un archivo que contiene las cartas originales, es revisado desde la película de Rísquez como si por medio de éste la protagonista quisiera dar a conocer otra verdad subyacente a los documentos que avalan la verdad de su contexto histórico. Así vemos, por ejemplo, que las cartas son tomadas por Manuela, aparentemente, en un orden secuencial, y en esa línea la protagonista va contando los momentos compartidos con Bolívar tal y como a ella se le va ocurriendo o según quien la vaya visitando. Al ser las cartas documentos desvencijados y al encontrarnos con el hecho de que las visitas de los personajes nos remiten a un pasado anterior al que 
la misma Manuela vivió con Bolívar, la narración que surge de la lectura e ilustración de los hechos sufre una dislocación temporal. También se debe tener en cuenta que las cartas viejas se encuentran en muy mal estado y que, muy probablemente, la escritura está borrosa. Por lo tanto, la narración de cada hecho se inicia con una carta, pero, dándole vida a la narración, lo que encontramos es que la historia narrada está sujeta, más que todo, a los recuerdos evocados por Manuela, una mujer bastante mayor y, además, no en muy buenas condiciones de salud. Todos los casos -la brecha temporal, el deterioro de los documentos y las remembranzas de Manuela- nos llevan a revisar la credibilidad que puede tener el baúl-archivo. De igual manera, nos remiten a encontrar una conexión entre Bolívar y la escritura histórica en torno a él mismo. Bolívar, presentado como el amor eterno de Manuela Saénz es reconstruido no sólo desde la figura heroica, sino desde los escritos que avalan tal imagen. Esa reconstrucción nos invita a leer entre líneas si la escritura afectada por condiciones externas, como el paso del tiempo o la dislocación de los hechos célebres, puede ser, a su vez, un paralelo de las interpretaciones, aplicaciones o usos que se han hecho de la escritura bolivariana. Es decir, por quienes, al igual que Manuela, han usado los documentos fidedignos a su propio antojo.

Esas cartas de amor que, igualmente, podrían ser vistas como una escritura subjetiva, deteriorada e incompleta, nos llevan a equiparar el baúl de Manuela con los archivos que hoy en día guardan el legado bolivariano en varios países libertados por él, y a formular la siguiente pregunta: ¿estarán, acaso, los documentos registrados en los archivos históricos también incompletos, caducos, inconexos? En la película, al ser las cartas de amor las únicas que respaldan el discurso histórico, la apropiación que se haga de éstas llegará a ser más relevante que la mención del personaje histórico que se referencia. Las hojas sueltas, que al final de la película aparecerán flotando por el aire, quedarán para contar otra verdad histórica posible. En ese punto, la nueva apreciación que se haga de tales cartas nos indica que ellas, que eran presentadas como documentos originales, al aparecer deshojadas, han sido desconectadas, muy seguramente, de las ideas iniciales que tuviera quien las envió. En la película, por estar estos escritos bajo la custodia de Manuela Sáenz, es ella quien le da el tono que desee ${ }^{7}$. De manera similar, las cartas flotantes seguirán siendo esas palabras de Bolívar que pueden tomarse según el orden y la apropiación que les sirva a varias personas en distintos momentos y circunstancias

\footnotetext{
${ }^{7}$ El tema de las múltiples apropiaciones de la figura y escritos de Simón Bolívar ha sido estudiado por varios críticos. El punto a resaltar en la película de Rísquez es la validación que busca ganar Manuela por medio de las cartas de amor. Veáse, por ejemplo, Harwich (2003).
} 
políticas o sociales. Mientras cada autor, director o representante político se apropie del discurso bolivariano y ponga en él toda la pasión requerida, como la que ha puesto Manuela, podrá crear una idea de verosimilitud.

Manuela, vista como quien ha posicionado su voz de testigo único y como la de alguien que, además, conoce a quiénes les interesa su historia, nos lleva de la mano para ampliar la mirada en torno a su amor eterno. En consecuencia, vemos, por ejemplo, que a Paita llegan varias personas a visitarla para que les cuente su historia sobre la vida de Bolívar. Aunque ella menciona que en el pasado ha habido más visitantes, en la película sólo se evidencia la presencia de Herman Melville, el autor de la novela Moby-Dick (1851) y Samuel Robinson, previamente conocido como Simón Rodríguez, el antiguo maestro de Bolívar. Melville ha venido con la intención de que le cuente la historia de Bolívar para escribir un libro. Su presencia, aparentemente, se ve como si fuera parte de un telón de fondo, pero en realidad su visita a la isla es trascendental, ya que este personaje nos permitirá enmarcar su historia dentro de la historia principal y luego engranarlas a través de varias piezas, aparentemente sueltas, dentro de la película. En el deseo que le expresa Melville a Manuela de querer escribir un libro sobre Bolívar se traza un hilo conector que muestra que las acciones que transcurrirán con la llegada de Melville no se quedan sólo en la interrelación que crea él con Manuela, sino que se vuelve extensiva al entorno y a las personas que los rodean.

\section{Melville: una historia que recoge varias historias posibles}

La llegada de Melville será definitiva en el desenlace de la película y ahora nos permitirá pasar a la segunda parte de este análisis. Este personaje será de suma importancia, ya que su presencia servirá para juntar varias partes de la historia central que parecían inconexas. Primero, debemos empezar por la primera idea que presenta Melville y esta es querer escribir un libro en torno a Bolívar. Al tener esta intención, Melville se presenta como el cronista que, al llegar al final de la historia, organizará los hechos y llevará la verdad al público. También debemos tener en cuenta que el contexto en que se enmarca la película es Perú, pero podría ser, igualmente, cualquiera de los países libertados por Bolívar. Del mismo modo, se debe anotar que el final que tendrá Manuela Sáenz podría ser, por extensión, el de cualquier ciudadano del país en el que ella vive.

Volviendo ahora sobre el personaje de Melville, concentrémonos en varios eventos que ocurren con su llegada a la isla. Entendemos 
que, primero, es necesario recordar que es un navegante y que ha llegado en su barco a Paita; segundo, que su deseo de recoger datos para escribir un libro en torno a la vida y obra de Simón Bolívar es el motivo por el cual se nos devela la historia que narra Manuela. Esta es la razón por la que, poco a poco, vamos sabiendo qué hechos serían dignos de estar en ese libro. Así, vamos de la mano de Melville contemplando, por medio de una recurrente técnica de flash-back, esas escenas del pasado, acompañadas de una fotografía y un fondo musical que nos remiten a la época, que nos muestran cómo era la relación entre Manuela y Bolívar. Las cartas funcionarán para Melville como información confiable que usará en sus futuros escritos, para avalar la verdad que pretende contar.

Melville no viene solo, sino que está acompañado por otros viajeros. Estos navegantes han contraído una extraña enfermedad, supuestamente, a causa de un polizón que fue hallado muerto en el barco. Este hecho se hace visible al llegar a tierra y a medida que se van infectando todas las personas de la isla, la enfermedad se va transformando en una especie de peste. Al final de la película, la única prueba de que en ese lugar hubo vida son las cartas de Bolívar que han quedado flotando por el aire, como si éstas reclamaran que alguien más continuara su historia. Al mostrar un final donde todas las personas perecen a causa del deseo de Melville, incluyendo a Manuela, se nos conduce a encontrar otras conexiones entre Bolívar y los textos escritos que posicionan su imagen heroica. Así, se debe tener en cuenta que la enfermedad que ha infectado a las personas de la isla la trajeron unos extranjeros. De este modo, se podría pensar que la película cuestiona, sutilmente, cuáles son los resultados al acoger extranjeros e ideas foráneas y querer implementar el sueño que ellos traen ${ }^{8}$. Para continuar, es relevante notar que la enfermedad tipo peste pareciera dar una señal de alerta en dos sentidos: uno que resalta que desde la pandemia se infectan todos los habitantes de la isla, pero también que, además de estos, también mueren los mismos portadores del virus o bacteria. Lo anterior conlleva a pensar que en las condiciones en las que habían llegado esos extranjeros, sus ideas no habrían dado fruto jamás, pues sus cuerpos venían deteriorados desde antes de entrar a la isla. Si bien es cierto que Melville es quien se supone será el cronista que publicará la nueva historia de Bolívar, también es evidente que, como viajero principal del grupo que ha traído la enfermedad, ha generado una gran problemática en el contexto que visita.

\footnotetext{
${ }^{8}$ Es importante resaltar que desde sus inicios Hugo Chávez Frías, desde su período de gobierno, mantuvo una fuerte relación con el gobierno de Cuba para programas políticos, de educación y salud, entre otros. Por eso la idea presentada por Rísquez parece sugerente en este contexto.
} 
De esta manera, Melville ha hecho extensiva, en símismo, las situaciones de dificultad que viven los personajes de su más reconocida novela, Moby-Dick. Esta condición, no obstante, lo transforma en el eslabón que nos permite establecer varias relaciones intra e intertextuales, que al final revelarán una imagen ampliada de la relación que se da a lo largo de la película entre Bolívar y la escritura proveniente del baúlarchivo usado para avalar otra verdad histórica. Por ahora, sabemos que Melville ha sacrificado la vida de su tripulación en busca de su sueño de hablar con Manuela Sáenz y poder dar a conocer el legado bolivariano por medio de su escritura. Sin embargo, con probabilidad no recordábamos que, paralelamente, en su libro Moby-Dick, el capitán que dirige el barco también sacrificará la vida de sus acompañantes por su insistente deseo de lograr su sueño de cazar la ballena blanca que da nombre a la novela. Es decir, la historia de Bolívar se entrecruza con la de Melville por medio de Manuela, y a su vez, se intersectan por medio de los escritos, los que tiene Manuela y los que tiene Melville. Como consecuencia de tal engranaje, por extensión, se encuentran varias historias, esta vez por medio de Melville: la del capitán del barco en Moby-Dick, la de Manuela, la de Bolívar y la del propio Melville, las cuales permitirán deshojar, más tarde, la historia más general que revisa Rísquez.

Desde su ilusión y pasión por narrar una nueva historia en torno a Bolívar, y tal vez todas las historias que de esa narración pudieran derivar, Manuela termina perdiendo su vida y la de sus dos fieles acompañantes, sus dos criadas, Jonatás y Natán. Por otra parte, encontramos que los escritos de Bolívar que quedan flotando en el aire se conectarán con los escritos de Melville, o con los que tiene en vía de escritura. En el caso de Melville, en su función como punto conector de historias y como futuro cronista, encontramos el personaje ideal que permite crear una relación intertextual entre el capitán del barco y Bolívar, y que nos lleva a recordar la frase de Bolívar al final de sus días: "He arado en el mar". Esta frase que los historiadores han enfatizado tantas veces revela que Bolívar, por ir en busca de su sueño de conformar una gran nación, terminó enfermo y en precarias condiciones que lo llevarían a la muerte. Situación semejante tanto para el capitán Abab como para Melville. El desastroso final de todos los implicados en la historia de Bolívar, historia que no pudo narrar Melville, sugiere, tácitamente, el final de una utopía, el sueño bolivariano, que, muy seguramente, se encuentra como las cartas de Manuela al final de la película, flotando en el aire.

Melville aparece, en todo caso, como esa figura que enlaza un hilo conductor en un punto común que une todas las historias: el fracaso por obtener un sueño. Así mismo, vale la pena observar que los 
papeles que flotan por el aire no son solamente las cartas de Bolívar, sino también las notas de Melville. De este modo, tanto el pasado representado en las cartas flotantes, que salieron del baúl-archivo, como el futuro que pretendía rescribir Melville, se han convertido en textos por terminar que requerirán de otro mecanismo para avalar la verdad. Al no poderse desarrollar la historia que planeaba contar Melville, la trama sugiere una invitación a los espectadores del filme a pensar si podrá existir un mejor final para la historia inconclusa entre Manuela y su eterno amor. El paralelismo que se ha trazado en la trama de la película entre el fracaso de Melville y el fracaso de Bolívar hace que la historia sobre Bolívar marque una ruptura con el pasado. De esta manera, parecería que Rísquez estuviera proponiendo que el sueño bolivariano que se puede culminar requiere que aún se junten las distintas partes que conlleven a un mejor final.

\section{Conclusión}

Podríamos decir que el tema de la enfermedad traída por Melville nos permite hacer varias relaciones intratextuales con otros elementos de la narración iniciada por la protagonista. El entorno infectado no afecta sólo a Manuela, sino que se hace evidente a través de cada personaje que la rodea. Este aspecto sirve para ilustrar que la discapacidad que sufre Manuela es algo más que una limitación física. Desde su exilio, ella ya no tiene voz ni voto en las decisiones políticas que se tomen en Colombia o Venezuela. Para alguien tan activo políticamente esta limitación física es más bien un reflejo de una limitación sicológica, política y social. El estado de paralización en que ha quedado Manuela sugiere que su destierro es una consecuencia sufrida por su desacuerdo con las ideas políticas del Presidente de la República de entonces, Francisco de Paula Santander. Al ser esta película presentada a principios del año 2000, esta salida forzosa de Manuela planteará otro tipo de exilio para aquellos venezolanos emigrantes de finales del siglo $\mathrm{XX}$ y las dos primeras décadas que se avecinarán del XXI; para quienes de una forma similar estén por fuera de la historia oficial o se identifiquen con la protagonista de la película de Diego Rísquez?

\section{Bibliografía}

Bushnell, David (2006). "What is the Problem with Santander", Estudios Colombianos, nำ 29, pp.12-18.

\footnotetext{
${ }^{9}$ El tema de las diferencias políticas y tensiones bipartidistas entre Bolívar y Santander es un tema recurrente tanto en los textos biográficos como en varios artículos críticos. Véase Bushnell (2006).
} 
Carrera Damas, Germán (1983). "El culto heroico y la nación”, Hispanic American Historical Review, vol. LXIII, nº 1, pp. 107-145. - (1989). El culto a Bolívar. Esbozo para un estudio de la historia de las ideas en Venezuela. Caracas: Grijalbo.

Castellanos, Dora (1999). Un hombre diáfano, Simón Bolívar: mujeres en su vida. Sinfonía en cuatro movimientos. Bogotá: Publicaciones de las Fuerzas Militares.

Conway, Christopher (2003). The Cult of Bolivar in Latin American Literature. Gainesville: UniversityPress of Florida.

Cordovez Moure, J. M. (1942). “Doña Manuela Sáenz”. En Reminiscencias de Santa Fé y Bogotá. Bogotá: Instituto gráfico Ltda.

García Márquez, Gabriel (2003). Crónica de una muerte anunciada. New York: Vintage.

González Echavarría, R. (1990). Myth and Archive. A Theory of Latin American Narrative. New York: Cambridge University Press.

Liévano Aguirre, Indalecio (2001). "Manuelita Sáenz". En Bolívar. Bogotá: Cargraphics S.A: https://www.fucsia.co/edicion-impresa/ articulo/las-mujeres-independencia/5684

Manrique Jaime (2011). “Una mujer adúltera”. En Nuestras vidas son los ríos. Bogotá: Nomos Impresores.

Márquez, Julia (2000): "Diego Rísquez al rescate de nuestra historia real y nuestra historia mística": http://www.analitica.com/ entretenimiento/diego-risquez-al-rescate-de-nuestra-historia-realy-nuestra-historia-mistica/ [Consultado el 15 de julio de 2017].

Mora, Orlando (2003). "Bolívar soy yo: entre la razón y la locura”: http:// cinelatinoamericano.org/texto.aspx?cod=126 [Consultado el 30 de noviembre de 2017].

Murray, Pamela S. (2001). "Loca or Libertadora?: Manuela Sáenz in the Eyes of History and Historians", Journal of Latin American Studies, vol. XXXIII, no 2, pp. 291-310.

Ospina, William (2010). En busca de Bolívar. Bogotá: Grupo Editorial Norma. Parra, Carlos Humberto (2000). (Des) construcción cultural y (re)construcción nacional: El Bolívar histórico en la narrativa latinoamericana a fines del siglo XX. Doctoral Dissertation, Duke University.

Paz Otero, Víctor (2008). Bolívar: delirio y epopeya. Bogotá: Villegas Editores.

Posada, Eduardo (1925). "La Libertadora", Boletín de Historia y Antiguedades, no 15 , pp. 17-38.

Quintero, Inés (2009). "Manuela Sáenz: una biografía confiscada": http://www.analitica.com/Bitblio/iquintero/manuela.asp> [Consultado el 12 de julio de 2009].

Rísquez, Diego (Director). (2000). Manuela Sáenz la libertadora del libertador. [DVD video]. Venezuela: Venevisión International.

Romero, Denzil. (1988). La esposa del Dr. Thorne. Barcelona: Tusquets.

Voltes Bou, Pedro. (1984). Adorable Loca. Barcelona: Plaza \& Janés. 